Portland State University

PDXScholar

1986

\title{
MMPI discrimination of incest offenders : a validity study of the IC, SV, and PE subscales
}

B. Joann Scheck

Portland State University

Follow this and additional works at: https://pdxscholar.library.pdx.edu/open_access_etds

Part of the Psychology Commons

Let us know how access to this document benefits you.

\section{Recommended Citation}

Scheck, B. Joann, "MMPI discrimination of incest offenders : a validity study of the IC, SV, and PE subscales" (1986). Dissertations and Theses. Paper 3701.

https://doi.org/10.15760/etd.5585

This Thesis is brought to you for free and open access. It has been accepted for inclusion in Dissertations and Theses by an authorized administrator of PDXScholar. Please contact us if we can make this document more accessible: pdxscholar@pdx.edu. 
AN ABSTRACT OF THE THESIS OF B. Joann Scheck for the Master of Arts in Psychology presented October 28, 1986.

Title: MMPI Discrimination of Incest offenders: A Valldity Study of the Ic, Sv, and Pe Subscales

APPROVED BY MEMBERS OF THE THESIS COMMITTEE:
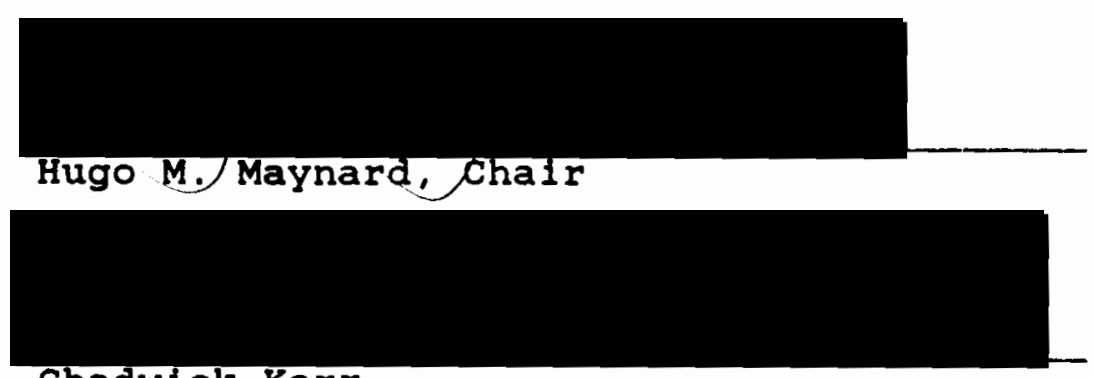

Chadwick Karr

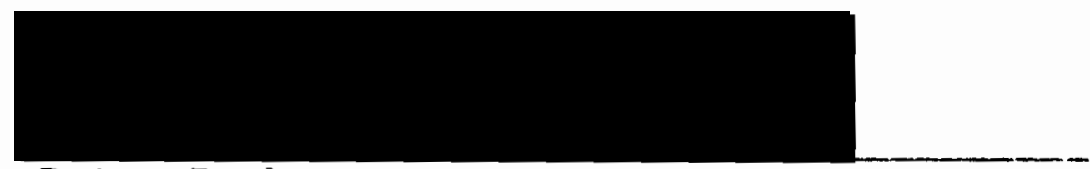

Peter Barbur

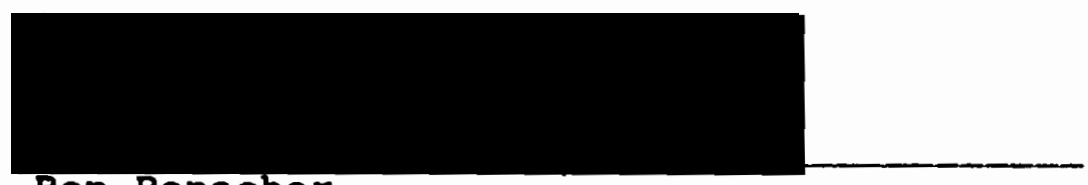

Ron Ronacher

This study examined the hypothesis that a set of MMPI items could be derived which would discriminate male incest offenders from male alcoholics. Second, the study investigated the validity of the $\underline{I C}, \underline{S V}$, and $\underline{P e}$ subscales by comparing the content and predictive efficiency of this set of discriminating items with these previously-derived subscales. MMPI (566-item) responses 
of 40 male incest offenders (fathers, stepfathers, and father surrogates who had committed sexual crimes against their children) and 40 male alcoholics (hospital treatment program patients with no known history of criminal sexual offenses and whose diagnosed substance use disorders included the use of alcoholl were compared by item analysis. Results were cross-validated with the responses of 40 additional offenders and 40 additional alcoholics. The 12 MMPI items which discriminated between offenders and alcoholics in both analyses comprised a final set of items, supporting the hypothesis that a set of discriminating items could be derived. However, this set of items did not provide support for the validity of the previously-derived subscales. None of the 12 discriminating MMPI items appeared in either the Ic or Pe subscales, and only 3 appeared in the Sv. Moreover, all three subscales falled to differentlate the incest offenders from the alcoholics in this study. These findings were consistent with previous $\underline{S v}$ and $\underline{P e}$ research in which the subscales differentiated sex offenders from "normal" males, but failed to differentiate offenders from pathological cross-validation groups. In addition, a finding that the MAC scale also failed to differentiate the two groups satisfactorily raised questions about the MAC scale's validity which may warrant further investigation. Due to 
the sensitivity of incest and the stigma involved in child sexual abuse, it is important that a scale for the identification of offenders be valid and reliable. Although the 12 items derived in this study might be worthy of further research, the results of the present study strongly indicated that the MMPI is not a suitable instrument for the derivation of such a scale. 
MMPI DISCRIMINATION OF INCEST OFFENDERS: A VALIDITY STUDY OF THE IC, SV, AND PE SUBSCALES

by

B. JOANN SCHECK

A thesis submitted in partial fulfillment of the requirements for the degree of

\author{
MASTER OF ARTS \\ in \\ PSYCHOLOGY
}

Portland State University

1986 
TO THE OFFICE OF GRADUATE STUDIES AND RESEARCH:

The members of the Committee approve the thesis of B. Joann Scheck presented October 28, 1986 .

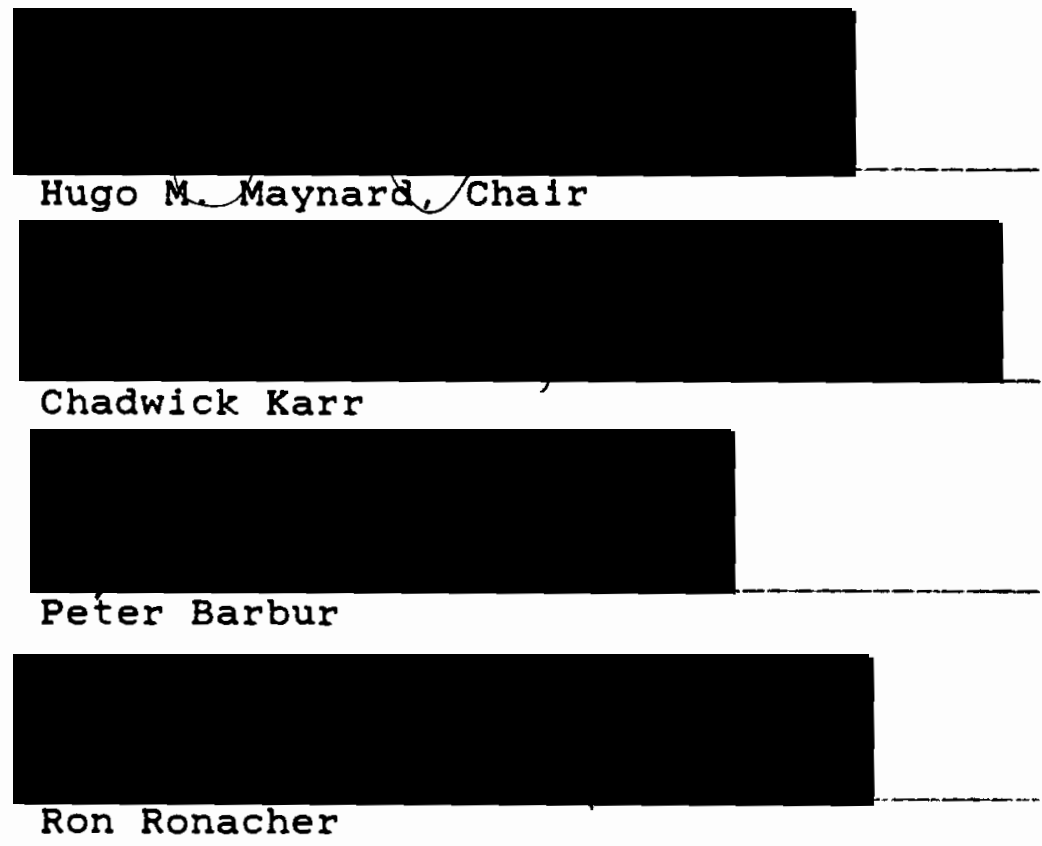

APPROVED :

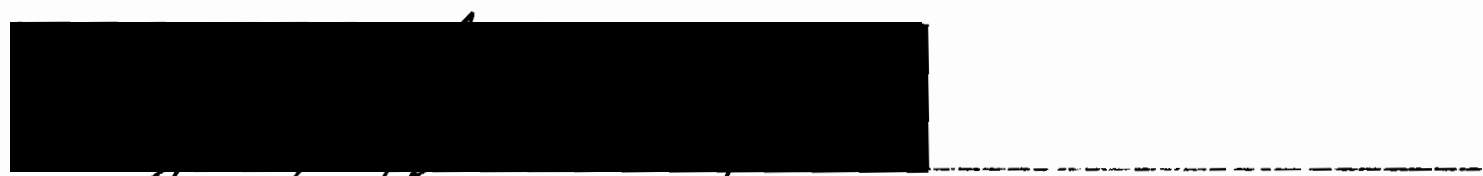

Rogef D. penflings, Head, Department of Psychology

Bernard Ross, Dean of Graduate Studies and Research 


\section{ACKNOWLEDGEMENTS}

I wish to express my sincere appreciation to all of the people whose help and encouragement made this study possible. I owe special thanks to Hugo Maynard, my thesis advisor, and to committee members Chadwick Karr and Peter Barbur for their expertise, ideas, and guidance throughout the process. I am also grateful to Ron Ronacher for his help as Portland State University's Graduate Representative. The data used in this study were obtained through the cooperation of Providence Medical Center with the assistance of Peter Barbur and Joel Miller. Mary Dolan provided me with helpful insights and suggestions. I was privileged to confer with Stanley Mazur-Hart and John Priollaud, Oregon State Hospital, and I am appreclative of their time and counsel. During the statistical analysis, Robert Kopp's facility with computers was invaluable. Frank Gebhard generously assisted me with the word processing. Finally, my thanks to John Scheck for his positive regard and enthusiastic support. 
TABLE OF CONTENTS

PAGE

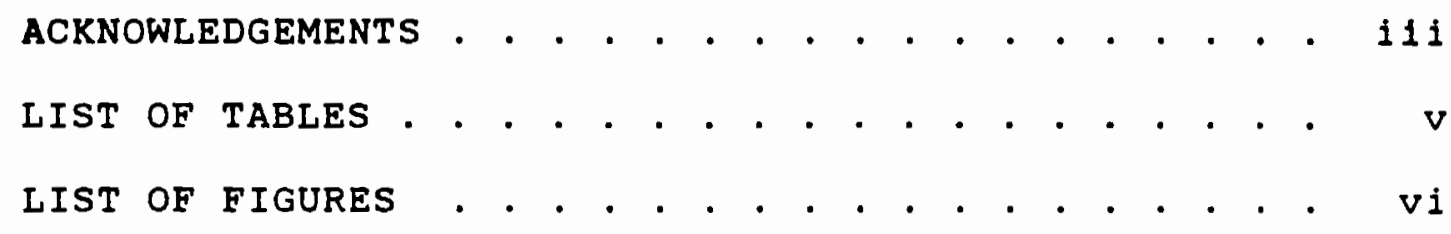

CHAPTER

I INTRODUCTION . . . . . . . . . . . . . 1

II METHOD . . . . . . . . . . . . . . . . 18

III RESULTS . . . . . . . . . . . . . . 24

IV DISCUSSION . . . . . . . . . . . . . . . 40

REFERENCES . . . . . . . . . . . . . . . . . . 49 49 


\section{LIST OF TABLES}

TABLE

PAGE

I Demographic Data for Combined Incest offenders and Combined Alcoholics. . . . . . . . 25

I Childhood Demographic Data Reported by

Combined Incest offenders and by Combined Alcoholics . . . . . . . . . . . . . 26

II Abuse Demographics . . . . . . . . . . . . . 28

IV Initial Item Analysis to Derive MMPI Items

to Discriminate Between Male Incest

Offenders and Male Alcoholics . . . . . 29

$V$ Second Item Analysis to Derive MMPI Items

to Discriminate Between Male Incest

Offenders and Male Alcoholics . . . . . 30

VI Final set of 12 MMPI Items Discriminating

Incest offenders and Alcoholics . . . 31-32

VII Percentages of Incest offenders and

Alcoholics Correctly and Incorrectly

Classified by Final set of 12 MMPI Items

and Sv, Pe, and Ic Subscales... . . . . 34

VIII Standardized Canonical Discriminant Coefficients

Applied to MMPI Validity, Clinical, and

Special Scale Mean K-Corrected $\underline{T}$-Scores . . 39 


\section{LIST OF FIGURES}

F IGURE

PAGE

1. Means and Standard Deviations for

X-Corrected MMPI Scale Scores for

Groups 1 and 3 (Combined Incest

Offenders, $\underline{N}=801$. . . . . . . . . . . 36

2. Means and Standard Deviations for

K-Corrected MMPI Scale Scores for

Groups 2 and 4 (Combined Alcoholics,

$\underline{N}=80$ ) . . . . . . . . . . . . . . . . 
CHAPTER I

\section{INTRODUCTION}

In a recent study, Dolan (1985) examined the hypothesis that "one salient, unique item scale can be empirically constructed on the basis of objective psychometric data, as provided by the MMPI" (Minnesota Multiphasic Personality Inventory). "that typifies the incest offender" (p. 13). Dolan found eleven MMPI items to be critical in discriminating male incest offenders from nonoffenders and designated this set of items as the Ic experimental subscale. Using empirical scale construction procedures of item selection and cross-validation (Clopton, 1978), Dolan derlved the Ic subscale by comparing the MMPI (short Form $R$ ) responses of three groups: 1) criterion group, 93 fathers and father surrogates found guilty of incest and evaluated by a hospital sex offenders program; 2) control group, 37 male college students with no known history of criminal sexual offenses: 3 ) experimental or cross-validation group, 33 incest fathers and father surrogates assessed by a licensed private practitioner. Criminal charges for combined Groups 1 and 3 included incest, sexual abuse, child molestation, indecent liberties, sodomy, and rape. 
The Ic scale (with a cutting score of 4 endorsed items) correctly classified $72 \%$ of the criterion group and $67 \%$ of the cross-validation group as offenders, whereas it incorrectly classified $8 \%$ of the control group.

Reliability of the 11-item scale, measured by the Kuder-Richardson formula 20, was $\alpha=.77, p<.0001$.

The increasing professional and public concern regarding the prevalence of incest has demonstrated the need for the identification, assessment, and treatment of incest offenders (Renshaw, 1982; Sgro1, 1982; Watson, Lubenow, Greenberg, King, \& Junkin, 1984). Despite the existence of an incest taboo (Freud, 1913/1946;

Lévi-Strauss, 1969; Lindzey, 1967; Parker, 1976), recent studies have indicated that the practice of incest is more pervasive than previously suspected (Banmen, 1982; Gelinas, 1983; Scherzer \& Lala, 1980; Vander Mey \& Neff, 1982; Westermeyer, 1978). Incest with children has been the primary focus of many of these studies and has been cited as a frequent but underreported form of sexual child abuse (Finkelhor, 1984; Russell, 1983). Because so many cases are not reported, the actual incidence of incest is unknown and must be estimated. For example, on the basis of a number of large surveys, Herman and Hirschman (1981) estimated that "between $20 \%$ and $35 \%$ of all women have had a childhood sexual encounter with an adult male, that $4 \%-12 \%$ of all women have had such an 
experience with a relative, and that about $1 \%$ of all women have been involved in father-daughter incest" (p. 967).

Estimates of incest vary considerably, partly due to differences in definition. Historically, a definition of incest has generally been limited to "sexual intercourse" between people "so closely related that they are forbidden by law to marry" (Webster, 1973, p. 580). More recently, researchers have broadened this definition to include a wider range of sexual activity. Finkelhor, for example, defined incest as "any kind of intentionally arousing contact to the sexual organs of one family member by another member" (1978, p. 41-42). Others have broadened the definition to include a wider degree of relationship. O'Hare and Taylor (1983) defined incest "as any act with sexual overtones perpetrated by a needed and/or trusted adult, whom a child is unable to refuse because of age, lack of knowledge, or the context of the relationship" (p. 215). Similarly, Dolan (1985) defined incest (based on Anderson and Shafer, 1979) as "the sexual mistreatment of a child by the father, by a close male family member, or by a male assuming the parent role (stepfather, mother's boyfriend, etc.) and encompasses all forms of sexual behavior from fondling to intercourse" (p. 12).

Legally, incest has been more narrowly defined. In 
the state of oregon, incest has been defined as marrying or engaging "in sexual intercourse or deviate sexual intercourse with a person whom the person knows to be related to the person, either legitimately or illegitimately, as an ancestor, descendant or brother or sister of either the whole or half blood" (Oregon Revised Statutes, 1985, p. 1648-1649). Therefore, this legal definition of incest does not include offenders who are surrogate parents (e.g.. stepfathers, foster fathers, various other close family members, or mothers' boyfriends). Neither does it include a number of sexual offenses such as sexual abuse of a person who is "considered incapable of consenting to a sexual act" or "any touching of the sexual or other intimate parts of a person or causing such person to touch the sexual or other intimate parts of the actor for the purpose of arousing or gratifying the sexual desire of either party" (Oregon Revised Statutes, 1985, p. 1646).

H. M. Maynard $(1984,1985,1986)$ has noted that the etymology of the word incest connotes sexual acts between people who are related and equal. Maynard has suggested, therefore, that "incest" is too benign a term to use for sexual acts in which a powerful parental figure betrays the trust and love of a dependent child. Maynard proposed that these sexual acts between unequal egos would be more accurately described as "child 
rape-seduction." Maynard has further suggested that "child rapists-seducers" should include all adults who misuse their privileged contacts and trust relationships to abuse children sexually, thereby putting them at risk for serious damage.

Some researchers have reported cases of incest between adults and children which seemed to cause little or no apparent harm (Bender \& Blau, 1937; Luklanowicz, 1972 ; Yorukoglu \& Kemph, 1966). However, most studies have indicated that incest results in severe and long-lasting psychological damage to the child (Becker, Skinner, Abel, Axelrod, \& Cichon, 1984; Brooks, 1985; Brown, 1979; Cohen, 1983; Gross, 1979; Green, 1982; James \& Meyerding, 1978). Some have hypothesized that brother-sister incest may actually be the most frequent type of incest and may also be harmful, especially if it involves an older brother and a younger sister (Cole, 1982: Finkelhor, 1981). Very few studies of mother-son (Arroyo, Eth, \& Pynoos, 1984; Margolis, 1984), father-son (Dixon, Arnold, \& Calestro, 1978; Langsley, Schwartz, \& Fairbairn, 1968; Raybin, 1969), and mother-daughter (Vander Mey \& Neff, 1984) incest have been reported, but the few avallable studies suggested that while these relationships may be less frequent, they are harmful to the child. In general, father-daughter incest is considered to be the most prevalent form of incest 
(Kempe, 1978) and has received the most attention in recent literature.

Several theoretical explanations for incestuous behavior have been proposed. From a psychodynamic perspective, the incest offender suffers from a defective ego which disorganizes and regresses. Consequently, the offender displaces unconscious hostility, fused with positive Dedipal strivings, from his mother onto his daughter (Cavallin, 1966; Freud, 1940/49). From a family perspective, the incest offender, together with the victim and spouse, comprise a pathological "interpersonal triangle" in which the nonparticipating spouse may foster the incest, sometimes overtly, but more often by collusion and denial (Machotka, Pittman, \& Flomenhaft, 1967). Viewing the incestuous family unit as analogous to a "character-disordered" individual, Anderson and Shafer (1979) postulated a "multiproblem family." Characteristics of this syndrome may apply to other family members as well as to the offender and include such difficulties as poor impulse control, poor judgment, conflicts with authority, manipulativeness, irresponsibility, little or no expression of guilt, callousness and narcissism, low anxiety, conflicts over dependency, and an inability to tolerate intimacy (American Psychiatric Association, 1980). The family perspective was elaborated by Lustig, Dresser, Spellman, 
and Murray (1966) as a "transactional pattern" which functions to reduce tension and maintain homeostasis in a dysfunctional family. A feminist perspective proposed that incest is one one of the forms of family violence which is produced in a male-dominated society (Breines \& Gordon, 1983).

Descriptive studies of incest offenders have produced generally consistent results. Weinberg (1955) found that incest offenders had often been raised in disorganized, emotionally deprived, sexually undisciplined families and seemed to have "emotional difficulties which facilitated impulsive behavior" (p. 101). Gebhard, Gagnon, Pomeroy, and Christenson (1965) described the incest offender of children as a man who is typically "rather ineffectual, nonaggressive, dependent . . drinks heavily, works sporadically, and is preoccupied with sexual matters" (p. 229). Of 50 offenders studied by Fowler, Burns, and Roehl (1983), 80\% were aged 31-45, 90\% were at least high school graduates, 80\% were abused either sexually or physicality as children, and $67 \%$ were substance abusers. These men were further characterized as self-centered, with poor impulse control, low self-esteem, low ego strength, few social skills, and were often domineering at home though mild-mannered in public. Many of the incest victims studied by Herman and Hirschman (1981) reported that 
incestuous fathers "tended to use physical force and intimidation to dominate their families" and were often "problem drinkers" (p. 968), but both the alcoholism and violence were controlled enough to escape outside detection and intervention. Justice and Justice (1979) described the typical incestuous father as symbiotic, expressing dependency needs in a sexual relationship with a daughter, and falling into one of several personality types: tyrant, introvert, rationalizer, or alcoholic. The MMPI has been used by numerous researchers to assess a wide variety of personalities (Dahlstrom \& Welsh, 1960). Dolan (1985) reviewed previous MMPI assessment of sex offender populations, particularly the assessment of incest offenders. In an MMPI study of 381 incestuous fathers convicted as felons, Cavaliin (1966) found evidence of "1) inadequate or weak object relations, 2) weak psychosexual identity, 3) unconscious homosexual strivings, and 4) projection as a major defense" (p. 1134). Using the MMPI and the sixteen Personality Factor Test (16 PF) to compare a variety of sexually anomalous males, Langevin, Paitich, Freeman, Mann, and Handy (1978) found a tendency for the incestuous males to have high scores on MMPI scales 2 (Depression), 6 (Paranoia), and 4 (Psychopathic Deviate), and from the $16 \mathrm{PF} E$ Factor (Humble-Assertive) determined them to be the "least assertive of all groups" (p. 235). 
In a study of 35 convicted incest offenders and 28 convicted child molesters, Panton (1979) found that incest offenders had higher MMPI scores on the 4, 2, and o (Social Introversion) scales, although the o scale was the only scale significantly different. Armentrout and Hauer (1978) compared MMPI group mean profiles of non-rapist sex offenders with rapists of adults and rapists of children. Although Armentrout and Hauer found modal two-point codes of $9-4$ and $4-8$ ( 9 is Hypomania and 8 is Schizophrenia) for non-rapist sex offenders, they warned that all three groups displayed heterogeneity which "cautions against arguing that the nature of the sex offense comitted allows accurate prediction of an individual's MMPI two-point code type" (p.332). Similarly, although Anderson, Kunce, and Rich (1979) found MMPI scores of 92 sex offenders (rape, child molestation, and incest) to yield three basic profile types $(F-8,4-9$, or 2-4), they concluded that "attempts to find specific profiles for certain crimes are not likely to be successful. Sex crimes.. . were not the only crimes or problems they had" (p. 675). Likewise, Kirkland and Bauer (1982) compared mean MMPI profiles of 10 male incest of fenders ( 5 fathers and 5 stepfathers) with 10 nonoffending fathers and stepfathers and found various elevated two-point scores for $90 \%$ of the incest of fenders. 
Previous experimental scales derived by comparing sex offenders with presumably "normal" control groups have generally proven unsuccessful in subsequent cross-validation studies, particularly in attempts to discriminate sex offenders from other pathological populations. One such experimental scale, the sexual Deviation scale (SV), was derived by Marsh, Hilliard, and Liechti (1955) by comparing MMPI responses of 100 convicted sex offenders with the MMPI responses of 100 male college students. The experimental group consisted of "men convicted of some sexual offense, the majority of which occurred with children, and committed to a state hospital for observation, diagnosis, and treatment" (p. 55). The control group consisted of undergraduate and graduate university students in the field of education, including principals, teachers, and superintendents. By an item analysis of the responses of both groups to each of the 566 MMPI items, Marsh, Hilliard, and Liechti identified 100 items which discriminated the sex offenders from the "normal" males. These 100 items, comprising the experimental Sv scale, were then used to score new samples of sex offenders and students in validation and cross-validation studies. Although $88 \%$ of the offenders (combined validation, cross-validation data) were classified correctly, $11 \%$ of the students were misclassified as offenders. However, 
in a subsequent validity study, MMPI responses of 100 mental patients (50 neurotic, 50 psychotic) were scored with the Sv scale, and the scale failed to discriminate these hospitalized mental patients from the sex offenders. Therefore, Marsh et al. (1955) cautioned that "despite the promising preliminary results," further validation studies should be made prior to clinical application, hypothesizing that "some factor of personality integration or adjustment is being measured by the scale" (p. 58).

A validity study of the Sv scale by Peek and Storms (1956) compared 13 hospitalized male sex offenders (4 molesters, 2 rapists, 2 homosexuals, 3 exhibitionists, 1 fetishist, 1 voyeur); 30 male mental patients (22 psychotics, 3 neurotics, 5 personality and character disorders): and 30 male psychiatric aides. The sv scale faijed to differentiate the sex offenders from either the mental patients or the psychiatric aides, and "correlations of the scale with other MMPI scales suggested that "the scale measures gross maladjustment or lack of personality integration" rather than sexual deviation (p. 135).

Several subsequent validity studies have reported similar results. In a study of Army males, the Sv scale was not successful in discriminating between 21 sexual deviates, 12 latent homosexuals, 42 diagnosed 
character disorders, and 30 "non-psychiatrics" (Holz, Harding, \& Glassman, 1957). Wattron (1958) used the SV scale to compare 60 imprisoned male sex offenders with 60 other types of felons, matching on age, race, and sex. The Sv scale failed to differentiate, and Wattron concluded the scale to be a "measure of gross maladjustment and. . of no practical value in discriminating between sex offenders and other type felons in correctional settings" (p. 16). Yamahiro and Griffith (1960) utilized the SV scale to compare 23 "normal" homosexuals (hospitalized during a legislated police round-up) and 110 hospitalized narcotic addicts. The scale failed to discriminate between the two groups, misclassifying $77 \%$ of the addicts as sexual deviates.

A second experimental scale designed to measure sexual deviation, the Pedophile scale (Pe), was derived by Toobert, Bartelme, and Jones (1959) by comparing MMPI responses of 120 male pedophile prisoners; 139 "normal" Minnesota males; and 160 male prisoners in general. The pedophiles were defined as persons whose "sexual object was a child (male or female) 12 years of age or under" (p. 273). MMPI data for the Minnesota males was cutained from S. R. Hathaway. The random sample of prisoners included all kinds of felons except those convicted of sexual crimes. Through a process of item analysis, the responses of the three groups to MMPI items produced a 
scale of 241 tems which discriminated between each of the three groups. In a series of cross-validation studies. the Pe scale was successful in differentiating both the original group of 120 pedophiles and a new group of 38 pedophiles from a second group of 50 male prisoners and a group of 55 male college "normals." However, the Pe scale did not differentiate between the pedophiles and a sample of 65 U.S. Army hospitalized psychiatric patients with neurotic and psychotic diagnoses. Toobert et al. (1959) analyzed the items that separated the pedophiles from the felons and college "normals," determining that the typical pedophile feels guilty, is inadequate soclally, dissatisfied sexually, sensitive to evaluation by others, and has strong religious concerns. The authors suggested that the pedophlles seemed to present more emotional maladjustment than other felons, and that the Pe scale "may be measuring a generalized neurotic or maladjustment factor" (p. 278-279).

In contrast to the $S v$ and Pe scales, Dolan (1985) noted that the Ic subscale was derived from a more "homogenous" sample ("all offenders were evaluated for possible inclusion in outpatient sexual offender treatment programs". and "pedophiles, rapists, exposers, or child molesters were excluded," p. 37). On the basis of this study, Dolan suggested that "the Ic scale offers practical utility as a psychological screening 
device for the objective identification of incest offenders, as well as for the assessment of potential incestuous behavior. Any male endorsing four or more of the Ic scale items can be viewed as at risk of being an incest offender. Further clinical evaluation may then be undertaken to confirm or refute this diagnosis" (p. 38). Dolan cautioned, however, that the validity, and thereby the clinical value, of the Ic subscale needed to be enhanced by replication studies. Dolan further noted that the predictive value of the Ic subscale was limited due to age, education, and socioeconomic differences between the groups of criterion offenders and control nonoffenders, suggesting that future replication studies control for these variables.

Replication studies are essential in the development of MMPI subscales in order to establish their reliability and validity. Graham (1977) discussed the clinical usefulness of experimental subscales, noting that more than 450 such scales have been developed. Graham warned that most of these scales are "not suitable for routine clinical use" because they have not been adequately cross-validated (p. 79). Cross-validation studies are especially essential in the development of a scale for the identification of offenders in an area as sensitive and as emotionally-laden as sexual offense and incest. 
In designing the present cross-validation study, several factors were considered. First, Dolan (1985) derived the Ic subscale using only the responses of male incest offenders and male nonoffender college students. Therefore, it was not known whether the Ic subscale would discriminate incest of fenders from male nonoffenders who were not college students. As Dolan noted, college males may differ from other males due to age, education, and socioeconomic factors. Second, the discriminatory power of the Ic subscale was likely $11 \mathrm{mited}$, due to the fact that it is comprised of only 11 items with a cutting score of 4. It was possible that a larger, more accurate subscale could be derived from responses to the 566-item MMPI. Third, previous studies had suggested that incest offenders may exhibit a variety of personality maladjustment factors (e.g., poor impulse control, low ego strength, conflicts with authority, emotional dependence, substance abuse) which may also be exhibited by many males who are not incest offenders. For example, MMPI research with alcoholic males has indicated that Scale 4 (Psychopathic Deviate) is the most frequently elevated scale (Levison, Gerstein, \& Maloff, 1983). In general, Scale 4 elevation has been associated with problems of impulse control, poor fudgment, conflicts with authority, etc. (Graham, 1977). In reviewing alcoholism research literature, Vaillant (1983) 
postulated that many such personality factors may actually be the result of alcoholism rather than its cause. Other than noting the complexity of the issues involved, a discussion of the etiology of alcoholism and the personality of the male alcoholic was beyond the scope of this present study. However, it was noteworthy that the Sv scale falled to discriminate between 23 male homosexuals and 110 male narcotic addicts, misclassifying 77\% of the hospitalized addicts as sexual deviants (Yamahiro \& Griffith, 1960). It was therefore essential that validity studies determine whether the Ic subscale would discriminate incest offenders from other males, such as alcoholics and addicts, who may exhibit similar factors of personality integration or adjustment.

The present validity study examined the hypothesis that a set of MMPI items could be derived which would discriminate male incest offenders from male alcoholics. Second, the study investigated the validity of the IC experimental subscale by comparing the content and predictive efflciency of this new set of discriminating items with the content and predictive efficiency of the Ic subscale. In addition, the validity of several previously-derived MMPI subscales (the Pe, Pedophile: Sv, Sexual Deviance; and MAC, MacAndrew Alcoholism) was also examined. The study differed from the previous studies in that it compared a narrowly-defined criterion 
group of sexual offenders (incest offenders) with a "non-normal" control group of nonoffenders (alcoholics), using responses to the 566 (rather than the 399) item MMPI .

The definition of incest offender used in this study was patterned after Dolan (1985), Maynard (1984, 1985), and the Oregon Revised Statutes (1985). For purposes of this study, "incest offenders" included fathers, stepfathers, and father surrogates (adult males assuming parental roles and relationships with dependent children, e.g., foster fathers, close male family members, mothers' boyfriends) who had committed sexual crimes against these children. Pedophiles (males whose primary sexual objects are children under the age of 12 but who have no parental relationship with these children), were excluded from the study. Many alcoholics have multiple substance use disorders (American Psychiatric Association, 1980). For purposes of this study, "alcoholics" included males whose hospital-diagnosed substance use disorder(s) included the use of alcohol. 
CHAPTER II

METHOD

SUBJECTS

In the initial analysis, individual MMPI item responses of two groups were compared. Group 1 , the criterion group, consisted of a total of 40 white male incest offenders 117 fathers, 18 stepfathers, and 5 father surrogates) who had committed sexual crimes against their children and were evaluated for treatment by the Providence Medical Center Day Treatment Sexual Offenders Program. Most of the Group 1 offenders had been formally charged, convicted, and remanded to Providence by Court order. Sexual criminal charges against Group 1 offenders included sexual abuse (29), sodomy (8), rape (7), incest (1), and indecent Iiberties (1). Ages of Group 1 offenders ranged from 23 to 53 years, with a mean age of 39.03 years. Years of formal education ranged from 9 to 19 , with a mean of 12.35 educational years. Number of marriages ranged from 0 to 4. mean 1.85: number of birth children ranged from 0 to 8. mean 2.35; and number of stepchildren ranged from 0 to 6, mean 1.08 . 
Group 2, the control group, consisted of a total of 40 white male alcoholics $(28$ inpatients and 12 outpatients with no known history of criminal sexual offenses and whose diagnosed substance use disorders included the use of alcohol) who were evaluated for treatment by the Providence Medical Center Alcohol Treatment Program. Ages of Group 2 alcoholics ranged from 27 to 62 years, with a mean age of 39.33 years. Years of formal education ranged from 9 to 19 , with a mean of 13.78 educational years. Number of marriages ranged from 0 to 5 , mean 1.43; number of birth children ranged from 0 to 6 , mean 1.78 ; and number of stepchildren ranged from 0 to 4 , mean 0.30 .

Item analysis results were cross-validated with the individual MMPI item responses of two additional samples. Group 3, the first cross-validation group, consisted of a new sample of 40 white male incest offenders 117 fathers, 18 stepfathers, and 5 father surrogates) who had committed sexual crimes against their children and were evaluated for treatment by the Providence Medical Center Day Treatment Sexual offenders Program. Most of the Group 3 offenders had been formally charged, convicted, and remanded to Providence by court order. Sexual criminal charges against Group 3 offenders included sexual abuse (28), sodomy (8), rape (6), and incest (3). Ages of Group 3 offenders ranged from 28 to 68 , with a 
mean age of 41.05 years. Years of formal education ranged from 7 to 17 , with a mean of 11.97 educational years. Number of marriages ranged from 1 to 4, mean 1.82; number of birth children ranged from 0 to 7 , mean 2.13; and number of stepchildren ranged from 0 to 4, mean 1.10 .

Group 4, the second cross-validation group, consisted of a new sample of 40 white male alcoholics ( 28 inpatients and 12 outpatients with no known history of criminal sexual offenses and whose diagnosed substance use disorders included the use of alcohol) who were evaluated for treatment by the Providence Medical Center Alcohol Treatment Program. Ages of Group 4 alcoholics ranged from 23 to 66 years, with a mean age of 40.58 years. Years of formal education ranged from 11 to 21 , with a mean of 14.13 educational years. Number of marriages ranged from 0 to 4, mean 1.23; number of birth children ranged from 0 to 7 , mean 2.30 ; and number of stepchildren ranged from 0 to 2 , mean 0.20 .

\section{MATERIALS}

MMPI records used in this study were item responses and scale scores from the first MMPI administered to the subjects during routine intake psychological evaluations by the respective treatment program. MMPI's were administered to Groups 1 and 3 (offenders) May 1980 
through May 1986 and consisted of 68 machine-scored Form R's, 11 hand-scored Form R's, and 1 hand-scored Group Form. MMPI's were administered to Groups 2 and 4 (alcoholics) July 1984 through December 1985 and consisted of 12 machine-scored Form R's, 37 hand-scored Form R's, and 21 machine-scored Group Forms.

\section{PROCEDURE}

All MMPI's were converted to machine-scored Form $R^{\prime} s$ by the researcher and sent to National Computer Systems (NCS) in Minneapolis, Minnesota. NCS machine-scored all MMPI's uniformly, providing an ASCII coded computer tape of item responses, raw scores, and standard $\underline{T}$-scores, and the data were analyzed with the Portland State University Honeywell main frame computer.

Demographic data were complled, as completely and as objectively as possible, from avallable records in the hospital files. The fact that these data were based largely on self-report in response to two differing intake interviewing processes must be taken into consideration when interpreting and evaluating the demographic statistical comparisons. In accordance with ethical guidelines, all MMPI records and demographic data were obtained from the files by permission of the appropriate authority and coded by subject number, ensuring the anonymity of subjects and maintaining strict 
standards of confidentiality.

This study was divided into two related investigations. During the first investigation, a set of MMPI items which discriminated between the male incest offenders and the male alcoholics was derived by following a series of procedures established by clopton (1978, 1982). First, an initial item analysis compared the 566 True and False MMPI response frequencies of the criterion Group 1 incest offenders with the responses of the control Group 2 alcoholics. A 2 × 2 contingency table was constructed for each of the 566 MMPI items (Incest vs. Alcoholic; True vs. False), and the items which significantly differentiated the two groups (those with significant chi-square values or contingency coefficients) made up an initial list of discriminating items. Second, the above process was repeated using the responses of the two cross-validation groups (Group 3 offenders and Group 4 alcoholics) resulting in a second initial list of discriminating items. Third, only those items appearing in both initial lists formed the final pool or set of discriminating items. Conducting two independent item analyses with criterion and cross-validation groups offered a solution to the problem of some of the 566 items reaching significance by chance. "The probability of an item reaching statistical significance by chance alone in two independent analyses 
would be quite low" (Clopton, 1978, p. 149). Finally, a cutting score to differentiate high scorers from low scorers was determined in order to maximize the number of incest offenders classified correctly and minimize nonoffenders classified incorrectly. All 160 MMPI's were then scored with the final set of items to determine its predictive efficiency.

This study also investigated the validity of several experimental MMPI scales. First, the MMPI items comprising the final set of items which was found to discriminate incest offenders from alcoholics was compared by inspection with the MMPI items comprising the Sv, Pe, and Ic subscales. Second, the $160 \mathrm{MMPI}$ answer sheets were scored with the SV, Pe, and Ic subscales, and the predictive efficiencies of each of the subscales was compared and evaluated. The MMPI answer sheets were also scored with the MacAndrew Alcoholism (MAC) scale to evaluate its predictive efficiency.

Finally, this study compared scoring by the incest offenders and the alcoholics on the 3 MMPI validity scales, the 10 clinical scales, and on 12 special scales. Two discriminant analyses were made to determine the relative predictive efficiency of the scale scores in discriminating between the incest offenders and the alcoholics. 


\section{CHAPTER III}

\section{RESULTS}

Demographic data were combined for Groups 1 and 3 (combined offenders) and Groups 2 and 4 (combined alcoholics) and are summarized in Table I. Analyses by t tests for a difference between two independent means demonstrated that there were no statistically significant differences in age between the combined offenders and the combined alcoholics or between the number of their birth children. Combined alcoholics had completed significantly more years of education, $\underline{t}(152)=-4.96$, $\mathbf{p}<.001$. Combined offenders had been married significantly more times, $\underline{t}(157)=3.71, \mathrm{p}<.001$, and had significantly more stepchildren, $t(158)=4.79$, $p<.001$. Combined alcoholics reported significantly more legal convictions involving alcohol, $t(158)=5.27$, p $<.001$, as well as significantly more legal convictions not involving alcohol, $\underline{t}(158)=2.29, \mathrm{p}<.05$.

Analyses by chi-square tests indicated that the combined offenders reported they had been abused sexually during childhood signiflcantly more than the combined alcoholics reported sexual abuse, $\underline{x}^{2}(1, \underline{N}=160)=$ 23.86, $\mathrm{p}<.001$. Combined offenders also reported 


\section{TABLE I \\ DEMOGRAPHIC DATA FOR COMBINED INCEST \\ OFFENDERS AND COMBINED ALCOHOLICS}

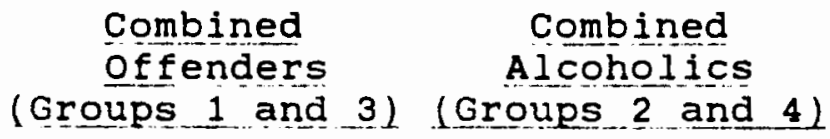

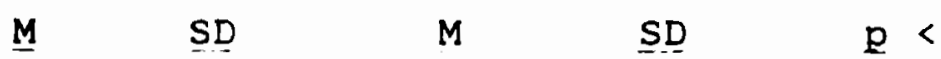

Age

$40.04 \quad(7.87)$

39.95

$(9.32)$

.949

Years of

education

$12.16(2.07)$

13.95

$(2.38)$

.001

Number of

marriages

$1.84 \quad(0.87)$

1.33

$(0.87)$

.001

Mumber of

birth children

$2.24(1.68)$

2.04

(1.54)

.433

Number of

stepchildren

$1.09 \quad(1.42)$

0.25

$(0.67)$

.001

Total number of children

$3.31(1.83)$

2.29

(1.73)

.001

Number of legal

convictions

(with alcohol)

$0.18(0.46)$

1.99

$(3.14)$

.001

Number of legal convictions

(without alcohol)

$0.10(0.33)$

0.40

$(1.06) \quad .05$ 
significantly more physical abuse during childhood than did the combined alcoholics, $\underline{x}^{2}(1, \underline{N}=160)=21.97$, $\mathrm{p}<.001$. Combined alcoholics reported significantly more parental alcoholism than did the combined offenders, $\left.\underline{x}^{2}(1, \underline{N}=160)=9.84, p<.005\right)$. There were no significant differences between the combined alcoholics and the combined offenders in reports of parental divorce or parental lack of affection. These results are summarized in Table II.

\section{TABLE II}

CHILDHOOD DEMOGRAPHIC DATA REPORTED

BY COMBINED INCEST OFFENDERS

AND COMBINED ALCOHOLICS

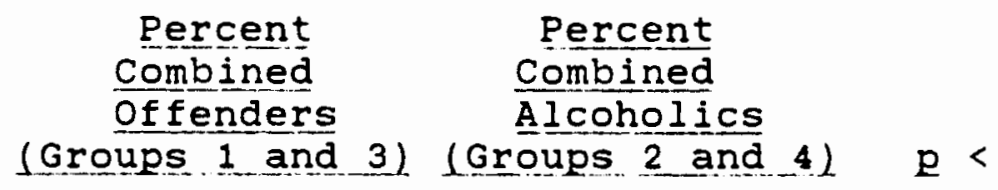

Physical abuse

during childhood

Sexual abuse

during childhood

Parental alcoholism during childhood

Parental divorce during childhood

Lack of affection during childhood
$39 \%$

$7.5 \%$

.001

$36 \%$

$5 \%$

.001

$24 \%$

$48 \%$

.005

$24 \%$

$33 \%$

.25

$66 \%$

$59 \%$

.50 
Demographic data specific to Group 1 (criterion) and Group 3 (cross-validation) incest offenders are listed in Table III. No statistically significant differences were found by comparing Group 1 and Group 3 offenders by number of victims, age of victim at onset of abuse, or age of victim at report of abuse. All but 2 (98\%) of the victims were female. Mean number of victims was 1.31 and 1.43 for Group 1 and Group 3 offenders respectively. Mean age at onset of abuse was 9.37 years for Group 1 victims and 8.33 years for Group 3 victims. Mean age at report of abuse was 12.38 years for Group 1 victims and 12.51 years for Group 3 victims. The type of sexual criminal charge was comparable for the two groups 163\% of the charges against combined offenders were sexual abuse, $17 \%$ were sodomy, $14 \%$ were rape, $4 \%$ were incest). Duration of sexual abuse was also comparable for the two groups, ranging from one contact with one victim to repeated contacts with four victims over a period of ten (or more) years. Additional analysis of the abuse demographics indicating no statistically significant differences between fathers and stepfather-father surrogates is also listed in Table III. The initial item analysis, comparing MMPI item-response frequencies of criterion Group 1 offenders and control Group 2 alcoholics, produced 54 MMPI items which significantly discriminated between the two groups, 
TABLE III

ABUSE DEMOGRAPHICS
A
B
C
D
E

Number of
victims
$\begin{array}{rl}M & 1.31 \\ S D & 0.57\end{array}$
1. 43
1.40
1. 35
1.37
0.81
0.75
0.67
0.70
Victim age abuse onset
M $\quad 9.37$
8. 33
3.17
8.83
8.78
8.85
SD
3.67
3.66
3. 65
3.42

Victim age

abuse report

M $\quad 12.38$

12.51

4.93

13.15

11.91

12.45

$S D$

3.70

4.08

4.51

4.34

Duration (yrs.)

of abuse

R $\quad 10.0$

8.0

10.0

10.0

10.0

Gender of

victim

Female

Male

$98 \%$

$2 \%$

$98 \%$
$2 \%$

$98 \%$

$2 \%$

$98 \%$
$2 \%$

$98 \%$

$2 \%$

Criminal

charges

Sexual Abuse

Sodomy

Rape

Incest

$\begin{array}{rrrrr}64 \% & 62 \% & 65 \% & 59 \% & 63 \% \\ 17 \% & 17 \% & 17 \% & 18 \% & 17 \% \\ 15 \% & 13 \% & 13 \% & 13 \% & 14 \% \\ 2 \% & 6 \% & 4 \% & 7 \% & 4 \%\end{array}$

A Group 1, criterion incest offenders, $\underline{N}=40$.

B Group 3 , cross-validation incest offeñders, $N=40$.

C Father incest offenders from combined Groups 1 and 3 . $N=34$.

D Stepfather and father surrogate incest offenders from combined Groups 1 and $3, \underline{N}=46$.

E Combined Groups 1 and 3 , all incest offenders, $N=80$. 
$x^{2}(1, \underline{N}=80), p<.02$. These initial items (Group

Form numbered according to MMPI convention) are listed with their phi coefficient values in Table IV.

\section{TABLE IV}

INITIAL ITEM ANALYSIS TO DERIVE MMPI ITEMS TO DISCRIMINATE BETWEEN MALE INCEST OFFENDERS AND MALE ALCOHOLICS

\begin{tabular}{|c|c|c|c|c|c|}
\hline MMPI & Phi & Subscale & MMPI & Phi & Subscale \\
\hline 1 & .36 & & 215 & -.58 & MAC \\
\hline 3 & .33 & & 217 & -.31 & \\
\hline 8 & .63 & & 240 & .31 & \\
\hline 9 & .35 & & 251 & -.37 & MAC \\
\hline 15 & -.33 & & 254 & -.33 & \\
\hline 36 & .39 & & 259 & -.35 & \\
\hline 37 & -.43 & Sv & 277 & -.48 & \\
\hline 39 & -.35 & Sv & 287 & .34 & \\
\hline 41 & -.39 & & 298 & -.32 & $\underline{S} \underline{v}$ \\
\hline 45 & -.38 & & 302 & -.46 & $\overline{s v}$ \\
\hline 51 & .40 & Sv & 318 & .55 & \\
\hline 84 & -.34 & $\underline{S v}$ & 340 & -.33 & \\
\hline 88 & .34 & sv & 344 & -.30 & \\
\hline 94 & -.37 & SV, MAC & 374 & -.33 & \\
\hline 95 & .45 & $\mathrm{Pe}$ & 378 & .34 & SV, MAC \\
\hline 98 & .32 & $\underline{\mathbf{s} v}$ & 396 & -.32 & \\
\hline 100 & -.43 & & 398 & -.34 & \\
\hline 116 & -.35 & MAC & 431 & -.41 & \\
\hline 119 & .36 & & 432 & -.30 & SV \\
\hline 137 & .35 & & 438 & -.33 & \\
\hline 142 & -.35 & & 446 & -.43 & MAC \\
\hline 152 & .35 & & 460 & .53 & SV, MAC \\
\hline 153 & .38 & & 466 & .35 & \\
\hline 156 & -.49 & MAC & 475 & -.38 & \\
\hline 166 & -.30 & & 522 & .32 & \\
\hline 186 & -.31 & MAC & 542 & .34 & \\
\hline 204 & -.40 & & 548 & .34 & Sv \\
\hline
\end{tabular}

MMPI MMPI Group Form item numbers.

$\underline{\text { Phi }}$

Item analysis phi coefficients. Positive coefficients indicate a greater proportion of offenders endorsed item "true"; negative coefficients indicate a greater proportion of offenders endorsed item "false"; $p<02$.

Subscale MMPI subscales in which items appear. 
The second item analysis produced 33 MMPI items which significantly discriminated between the cross-validation Group 3 offenders and Group 4 alcoholics, $\underline{x}^{2}(1, \underline{N}=80), \underline{p}<.02$ and are listed in Table V.

\section{TABLE V}

SECOND ITEM ANALYSIS TO DERIVE MMPI ITEMS TO DISCRIMINATE BETWEEN MALE INCEST OFEENDERS AND MALE ALCOHOLICS

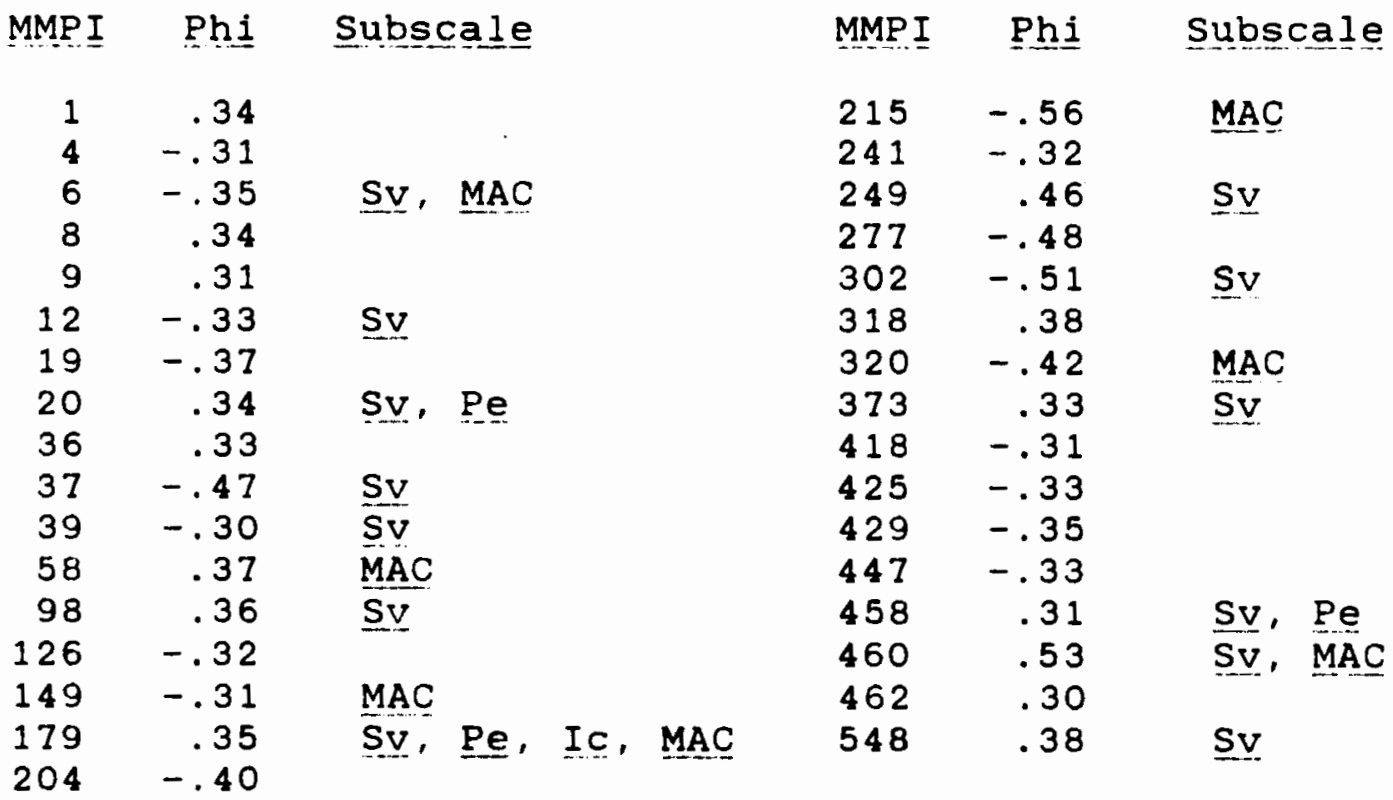

MMPI MMPI Group Form item numbers.

Phi Item analysis phi coefficients. Positive coefficients indicate a greater proportion of offenders endorsed item "true"; negative coefficients indicate a greater proportion of offenders endorsed item "false": $p<.02$.

Subscale MMPI subscales in which items appear.

Fourteen of the items (including two duplicate or repeating MMPI items) differentiated in both analyses. These 12 items (the 2 duplicates eliminated) comprised 
the final set of items which discriminated between the offenders and alcoholics ( $p<.0004)$ and are listed in Table VI.

\section{TABLE VI}

FINAL SET OF 12 MMPI ITEMS DISCRIMINATING INCEST OFFENDERS AND ALCOHOLICS

$\underline{I I}$

$\underline{I I I} \quad \underline{I V}$

$\underline{v}$

$\underline{V I}$

$\underline{\text { VII }}$

$\underline{I} \quad \underline{T} \quad \underline{T}$

1 I like mechanics magazines.

$\begin{array}{lrrrr}\text { Inc } & 32 & 8 & 35 & 5 \\ \text { Alc } & 23 & 17 & 18 & 22\end{array}$

$\mathbf{T}$

5

$\mathbf{F}$

B My daily life is full of things that keep ne interested.

$\begin{array}{lrrrrrrrrr}\text { Inc } & 32 & 8 & 33 & 7 & T & 2,3,4,7,8 & \text { F } \\ \text { Alc } & 7 & 33 & 20 & 20 & & \end{array}$

9 I am about as able to work as I ever was.

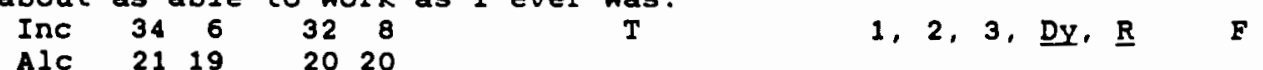

Alc $2119 \quad 2020$

36 I seldom worry about my health.

$\begin{array}{lllllll}\text { Inc } & 28 & 11 & 30 & 10 & T & 2,7 \\ \text { Alc } & 13 & 27 & 17 & 23 & & \text { Es }\end{array}$

F

37 I have never been in trouble because of my sex behavior.

$\begin{array}{lrrrrrr}\text { Inc } & 14 & 26 & 13 & 26 & F & 4 . \text { SV } \\ \text { Alc } & 31 & 9 & 32 & 8 & & \end{array}$

39 At times I feel like smashing things.
Inc 1129
1327
Alc
$25 \quad 15$
2515
$\underline{\underline{K}}, 2, \underline{\mathrm{R}}, \underline{\mathrm{SV}}$
F

98 I believe in the second coming of christ.
Inc $31 \quad 7 \quad 2910$
$\mathrm{T}$
2, Sv, Lb
Alc $20 \quad 19 \quad 15 \quad 24$
DY, REL

204 I would like to be a journalist.

Inc 337 3 37

F

5

$\mathbf{T}$

215 I have used alcohol excessively.
Inc
2020
1921
F, 4, MAC

$\mathbf{T}$

277 At times I have been so entertained by the cleverness of a crook that I have hoped he would get by with it.
Inc 832
733
Alc $27 \quad 13 \quad 26 \quad 14$

(Table VI Continued on next page) 
TABLE VI

(Continued)

$\underline{I} \quad \underline{I I} \quad \underline{I I I} \quad \underline{I V}$

460 I have used alcohol moderately (or not at all).

$\begin{array}{lrrrrrrrr}\text { Inc } & 37 & 7 & 29 & 11 & \text { MAC } & \text { T } & & \end{array}$

548 I never attend a sexy show if I can avold 1 t.

$\begin{array}{lrrrrrrr}\text { Inc } & 14 & 26 & 16 & 24 & \text { Eg } & \text { F } & \text { F } \\ \text { Alc } & 3 & 37 & 3 & 37 & & \end{array}$

- 302 I have never been in trouble because of my sex behavior.

Inc $\quad \begin{array}{llll}15 & 25 & 13 & 27\end{array}$

4

$\mathbf{F}$

AIC $\begin{array}{llll}33 & 7 & 33 & 7\end{array}$

- 318 My dally life is full of things that keep me interested.

$\begin{array}{llllllll}\text { Inc } & 33 & 7 & 31 & 9 & 2,3,4,7,8 & F \\ \text { Alc } & 11 & 29 & 16 & 24 & & \end{array}$

MMPI 1 tem number.

MMPI 1tem statement.

Number of true/false responses in initial item analysis.

Number of true/false responses in cross-validation item analysis.

Item scoring direction for final set of 12 1tems.

MMPI scales and subscales in which 1 tem appears.

Item scoring direction for listed MMPI scales and subscales.

Incest of fenders.

Alcoholics.

Duplicate MMPI Item (eliminated from final set of 121 tems

discriminating incest offenders and alcoholics).

As noted previously, the method of accepting only those items which discriminated in two independent 1tem analyses was necessitated by the large number of

statistical comparisons and (according to clopton, 1978) reduced the likelihood that items would discriminate by chance to a "very low" probability. Reliability of the final set of items, measured by Kuder-Richardson formula 20, Yielded $\alpha=.74, \underline{F}(11,149)=23.97, \mathrm{p}<.00001$, indicating a high degree of internal homogeneity among the items.

To score the MMPI's with the final set of items, 
one point was given for each of the 12 items answered in the deviant (offender) direction. Using a cutting score of 5 (arbitrarily determined to be the score which would maximize correct classification of offenders and minimize incorrect classification of nonoffenders) the final set of items correctly classified $92.50 \%$ of the criterion Group 1 offenders and $90 \%$ of cross-validation Group 3 offenders, for a total of $91.25 \%$ correct classification of combined offenders. Of the alcoholics, 5\% of control Group 2 and $10 \%$ of cross-validation Group 4 were classified incorrectly, for a total of $7.50 \%$ combined alcoholics misclassified as offenders (see Table VII).

MMPI answer sheets for Groups 1 and 3 (combined offenders) and Groups 2 and 4 (combined alcoholics were scored with the $I \underline{c}, \underline{S v}$, and Pe subscales. All of these subscales failed to discriminate satisfactorily between the combined incest offenders and the combined alcoholics, misclassifying high percentages of nonoffenders as offenders. Although the Sv subscale correctly classified $81.25 \%$ of Group 1 and Group 3 combined incest offenders, it misclassified $77.5 \%$ of Group 2 and 4 combined alcoholics as offenders. The Pe scale correctly classified $70 \%$ of the offenders, but incorrectly classified $57.5 \%$ of the alcoholics as offenders. The Ic scale produced a slightly greater percentage of false positives than correct positives, 
correctly classifying only $62.5 \%$ of the offenders while misclassifying $63.75 \%$ of the alcoholics as offenders (see Table VII.)

TABLE VII

PERCENTAGES OR INCEST ORYRNDERS AND ALCOHOLICS CORRECTLY AND INCORRECTLY CLASSIFIED BY EINAL SET OF 12 MMPI ITEMS AND SV. PE, AND IC SUBSCALES

\begin{tabular}{|c|c|c|c|c|c|c|}
\hline \multirow{2}{*}{$\frac{\text { MMPI }}{\underline{\text { Set }}}$} & No. of & Cutting & \multicolumn{2}{|c|}{ Combined Offenders } & Combined & Alcoho \\
\hline & Items & Score & $\begin{array}{l}\text { Correctly } \\
\text { classified }\end{array}$ & $\begin{array}{l}\text { Incorrectly } \\
\text { Classifled }\end{array}$ & $\begin{array}{l}\text { Correctly } \\
\text { classified }\end{array}$ & $\begin{array}{l}\text { Incorrect } \\
\text { Classif } 1 e\end{array}$ \\
\hline$\frac{\text { Final }}{\text { Set }}$ & 12 & 5 & $91.25 x$ & $8.75 \%$ & $92.50 x$ & $7.50 x$ \\
\hline$\underline{\text { Sv }}$ & 100 & 31 & $81.25 x$ & $28.75 x$ & $22.50 x$ & $77.50 x$ \\
\hline$\underline{\text { Pe }}$ & 24 & $\mathbf{8}$ & $70.00 *$ & $30.00 x$ & $42.50 \%$ & $57.50 \%$ \\
\hline IC & 11 & 4 & $62.50 x$ & $37.50 \%$ & $36.25 x$ & $63.75 \%$ \\
\hline
\end{tabular}

MMPI answer sheets for Groups 1 and 3 (combined offenders) and Groups 2 and 4 (combined alcoholics) were also scored with the MAC (MacAndrew Alcoholism scale). using 24 as the cutting score. Forty offenders (50\%) had a known history of alcohol and/or chemical abuse. The MAC scale classified $63.76 \%$ of the combined alcoholics and 55\% of the combined offenders (with a known history of alcohol and/or chemical abuse) correctly. of the incest offenders (with no known history of alcohol and/or chemical abuse) $40 \%$ were misclasstfied as alcoholics.

Mean MMPI $\underline{\mathbf{K}}$-corrected raw scores and $\underline{\mathbf{T}}$-scores, computed for Groups 1 and 3 (combined offenders) and for Groups 2 and 4 (combined alcoholics) for each of the validity and clinical scales and for 12 special scales, 
are found in Figures 1 and 2 . Analysis by $t$ tests for $a$ difference between two independent means indicated that combined offenders had statistically significant higher scores only on validity scales $\underline{I}$ (Lie), $\mathrm{p}<.001$, and $\mathrm{K}$, $\mathrm{p}<.005$; and on special scales Es (Ego Strength), $\mathbf{p}<.005$, and Re (Social Responsibility), $\mathbf{p}<.006$, in comparison with combined alcoholics. Combined alcoholic scale scores were significantly higher than the combined offender scores on validity scale $\underline{F}, \underline{p}<.004$; on clinical scales 2 (Depression), $\mathrm{p}<.001$; 3 (Hysteria), $\mathrm{p}<.04 ; 4$ (Psychopathic Deviate), $\mathrm{p}<.007 ; 5$ (Masculinity-Femininity), $\mathbf{p}<.001 ; 7$ (Psychasthenia), $p<.001 ; 8$ (Schizophrenia), $\mathrm{p}<.003 ; 9$ (Hypomania). $\mathrm{P}<.001$; and on special scales A (Anxiety), $\mathrm{Q}<.001$; MAC (MacAndrew Alcoholism), $\mathrm{p}<.01$; Lb (Low Back Pain), $\mathrm{p}<.02$; Ca (Cauda11ty), $\mathrm{p}<.001$; Dy (Dependency). $\underline{p}<.003 ;$ st (Social status), $\mathrm{p}<.003$; and $\mathrm{Cn}$ (Control), $\mathbf{p}<.001$

The most frequently elevated clinical scale score for Groups 1 and 3 (combined offenders) was scale 4 (Psychopathic Deviate), followed by scale 2 (Depression). There was no modal high-point pair for offenders. The most frequently elevated clinical scale scores for Groups 2 and 4 (combined alcoholics), in descending order, were scales 4 (Psychopathic Deviate), 2 (Depression), 7 (Psychasthenia) and 8 (Schizophrenia). The modal 


\section{DIIIIPI}

MINNESOTA MULTIRHASIC TW

3.R. Hoikowery end I.C. MeKinity

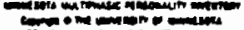

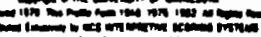

200

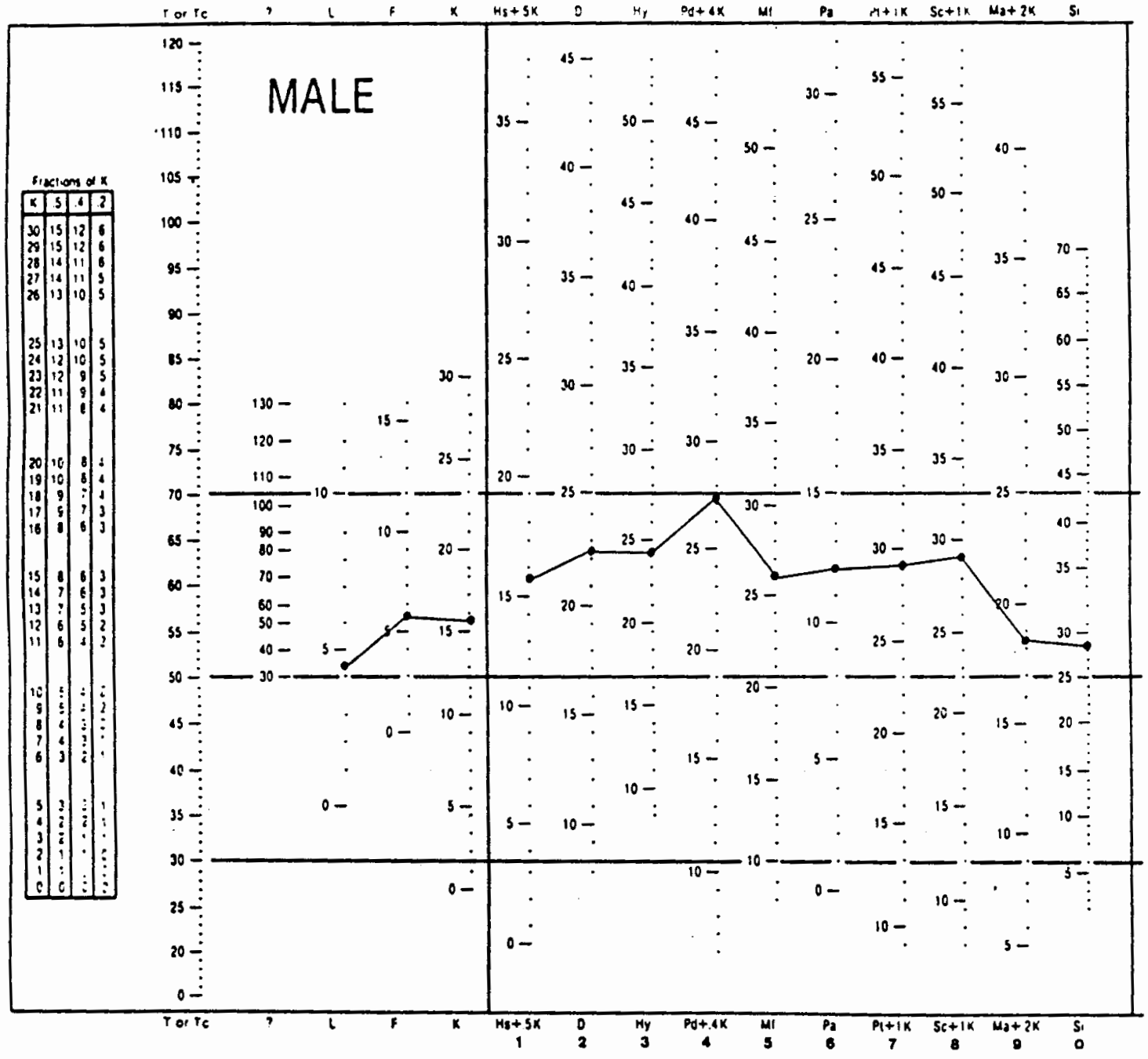

\begin{tabular}{|c|c|c|c|c|c|c|c|c|c|c|c|c|}
\hline $\begin{array}{r}\text { I Row Score: } \\
\text { SD: }\end{array}$ & $\begin{array}{l}4.5 \\
2.2\end{array}$ & $\begin{array}{l}6.1 \\
3.7\end{array}$ & $\begin{array}{r}16.1 \\
5.1\end{array}$ & $\begin{array}{r}15.7 \\
5.3\end{array}$ & $\begin{array}{r}22.5 \\
6.3\end{array}$ & $\begin{array}{r}24.1 \\
5.6\end{array}$ & $\begin{array}{r}27.2 \\
4.6\end{array}$ & $\begin{array}{r}26.2 \\
4.6\end{array}$ & $\begin{array}{r}12.1 \\
3.3\end{array}$ & $\begin{array}{r}29.0 \\
5.9\end{array}$ & $\begin{array}{r}29.0 \\
6.2\end{array}$ & $\begin{array}{r}18.0 \\
3.8\end{array}$ \\
\hline $\begin{array}{l}\text { A T Score: } \\
\text { SD: }\end{array}$ & $\begin{array}{r}51.4 \\
7.1\end{array}$ & $\begin{array}{r}57.3 \\
8.2\end{array}$ & $\begin{array}{r}57.1 \\
9.5\end{array}$ & $\begin{array}{l}61.2 \\
13.5\end{array}$ & $\begin{array}{l}64.1 \\
15.1\end{array}$ & $\begin{array}{l}63,9 \\
10.2\end{array}$ & $\begin{array}{l}69.6 \\
10.8\end{array}$ & $\begin{array}{r}61.4 \\
9.1\end{array}$ & $\begin{array}{r}62.0 \\
9.6\end{array}$ & $\begin{array}{l}62.3 \\
12.2\end{array}$ & $\begin{array}{l}63.0 \\
12.0\end{array}$ & $\begin{array}{r}54.8 \\
9.5\end{array}$ \\
\hline & $\underline{A}$ & $\underline{\mathbf{A}}$ & $\underline{E S}$ & $M A C$ & LB & CA & or & $\underline{D O}$ & $\underline{\mathrm{RE}}$ & $\underline{P R}$ & $\underline{\text { SI }}$ & $\mathrm{CN}$ \\
\hline $\begin{array}{r}\text { I Raw Score: } \\
\text { SD: }\end{array}$ & $\begin{array}{r}11.5 \\
8.5\end{array}$ & $\begin{array}{r}17.7 \\
4.7\end{array}$ & $\begin{array}{r}45.3 \\
6.3\end{array}$ & $\begin{array}{r}23.5 \\
4.1\end{array}$ & $\begin{array}{r}11.1 \\
2.4\end{array}$ & $\begin{array}{r}12.0 \\
5.9\end{array}$ & $\begin{array}{r}21.1 \\
9.5\end{array}$ & $\begin{array}{r}15.6 \\
3.6\end{array}$ & $\begin{array}{r}20.5 \\
3.9\end{array}$ & $\begin{array}{l}9.4 \\
5.2\end{array}$ & $\begin{array}{r}20.0 \\
3.7\end{array}$ & $\begin{array}{r}24.2 \\
4.7\end{array}$ \\
\hline $\begin{array}{r}\text { Mi Score: } \\
\text { SD: }\end{array}$ & $\begin{array}{l}49.1 \\
10.6\end{array}$ & $\begin{array}{r}54.5 \\
9.9\end{array}$ & $\begin{array}{l}51.6 \\
10.1\end{array}$ & $\begin{array}{l}54.4 \\
11.8\end{array}$ & $\begin{array}{l}58.0 \\
10.1\end{array}$ & $\begin{array}{l}54.4 \\
11.0\end{array}$ & $\begin{array}{l}52.0 \\
10.5\end{array}$ & $\begin{array}{l}52.3 \\
10.1\end{array}$ & $\begin{array}{r}50.7 \\
9.4\end{array}$ & $\begin{array}{r}45.7 \\
9.5\end{array}$ & $\begin{array}{r}55.3 \\
8.4\end{array}$ & $\begin{array}{l}48.4 \\
12.0\end{array}$ \\
\hline
\end{tabular}

Figure 1. Means and standard deviations for K-corrected MMPI scale scores for Groups 1 and 3 (combined incest offenders, $N=80$ ). 


\section{DIIIIPI DI}

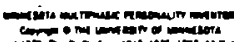

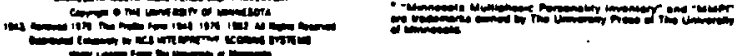

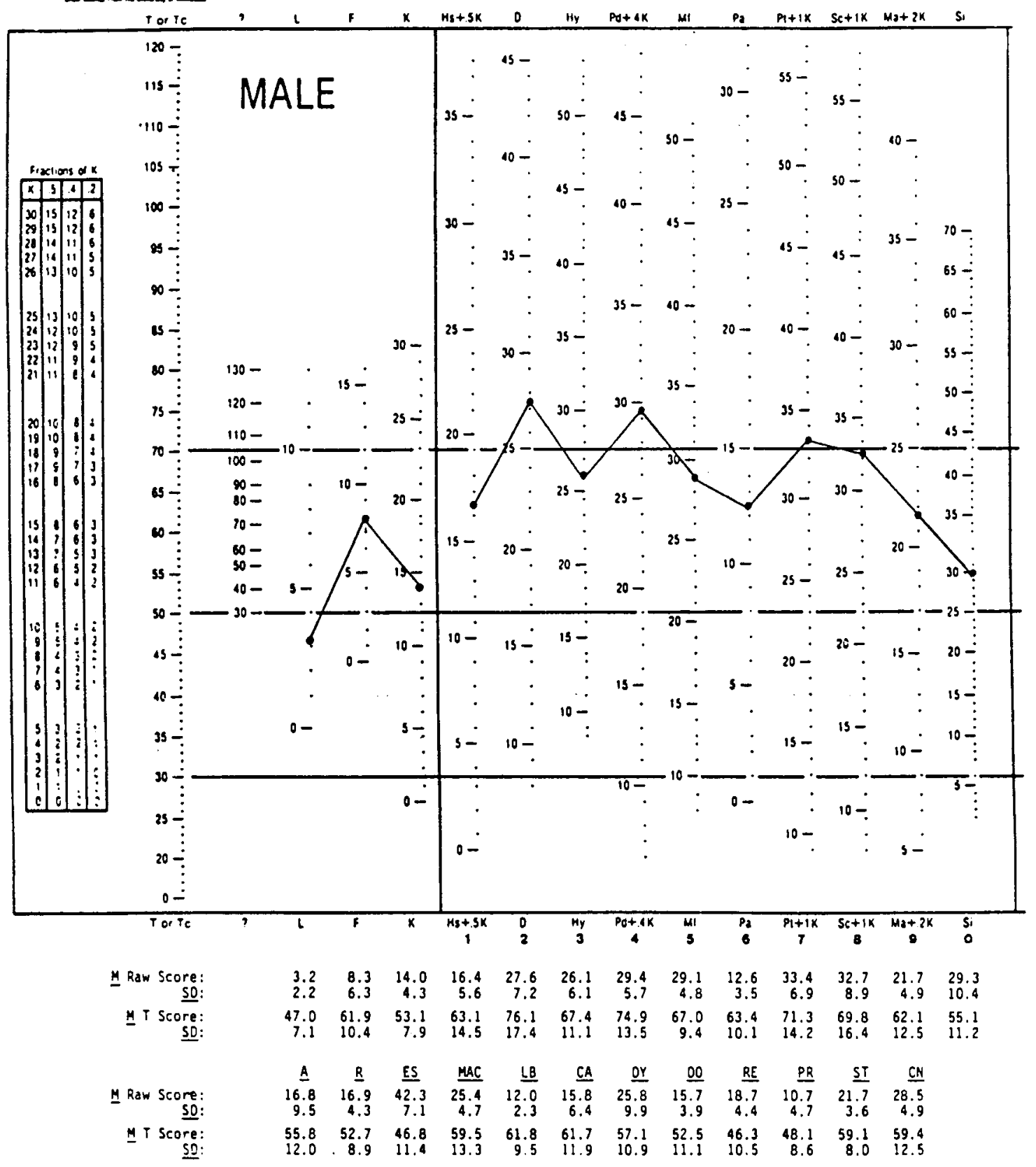

Figure 2. Means and standard deviations for $\underline{K}$-corrected MMPI scale scores for Groups 2 and 4 (combined alcoholics, $\underline{\mathbf{N}}=80$ ). 
high-point pair for combined alcoholics was $2-7 / 7-2$, and modal high-point triads were $2-7-8 / 7-2-8$ and $2-7-4 / 7-2-4$. An inttial discriminant analysis using the 3 MMPI validity and 10 clinical scale mean $\underline{K}$-corrected $\underline{\text { I-scores }}$ resulted in an $80 \%$ correct classification of combined incest offenders and a $72.5 \%$ correct classification of combined alcoholics, $\underline{x}^{2}(13)=69.08, p<.0001$. The standardized canonical discriminant function coefficients (listed in Table VIII) indicated that the scales which predominated in discriminating combined incest offenders from combined alcoholics (in descending order) were clinical scales 2 (Depression), 1 (Hypochondriasis), 7 (Psychasthenia), 6 (Paranoia), and 10 (Social Introversion). A second discriminant analysis, adding 12 MMPI special scale mean $\underline{T}$-scores, increased the correct classification of combined incest offenders to $83.8 \%$ and the correct classification of combined alcoholics to 81.3\%, $\underline{\mathrm{x}}^{2}(25)=90.51, \mathrm{p}<.0001$. These standardized canonical discriminant function coefficients (also listed in Table VIII) indicated that the scales which predominated in discriminating combined incest offenders from comblned alcoholics were scales A, (Anxiety), 2 (Depression), 7 (Psychasthenia), 1 (Hypochondriasis), and 6 (Paranoia). 
TABLE VIII

STANDARDIZED CANONICAL DISCRIMINANT COEFFICIENTS APPLIED TO MMPI VALIDITY, CLINICAL, AND SPECIAL SCALE

MEAN K-CORRECTED T-SCORES

Scale

$\frac{\mathrm{L}}{\mathrm{F}}$

2

3

4

5

6

7

8

9

10

A

R

ES

MAC

$\underline{\mathrm{Lb}}$

$\mathrm{Ca}$

DY

Do

Re

Pr

st

$\underline{\underline{\mathrm{Cn}}}$
Lie

Fake

Hypochondriasis

Depression

Hysteria

Psychopathic Deviate

Masculinity-Femininity

Paranola

Psychasthenia

Schizophrenia

Hypomania

Social Introversion

Anxiety

Repression

Ego Strength

MacAndrew Alcoholism

Low Back Pain

Caudality

Dependency

Dominance

Social Responsibility

Prejudice

Social status

Control
I

I I

Coefficient

$-0.37589$

$-0.17581$

0.40430

0.18649

0.17660

$-0.58650$

$-0.58720$

$-0.78734$

0.89729

0.82529

0.26278

0.24962

$-0.29771$

0.27851

$-0.39212$

0.29213

$-0.55470$

$-0.59231$

0.57510

0.81167

$-0.21118$

0.28078

0.42223

0.28046

$-0.52132$

$-0.23784$

$-1.51896$

0.15038

0.05756

0.33868

0.43347

0.39810

0.41585

0.10832

$-0.20305$

$-0.26470$

0.28589

0.06407

I Standardized canonical coefficients resulting from initial discriminant function using MMPI validity and clinical scale mean $\underline{K}$-corrected $\underline{T}$-scores.

II Standardized canonical coefficients resulting from second discriminant function adding MMPI special scale mean $\mathrm{T}$-scores. 


\section{CHAPTER IV}

\section{DISCUSSION}

The 12 MMPI items derived in this study accurately classified a high percentage of both the combined male incest offenders $(91.25 \%)$ and the combined male alcoholics $(92.5 \%)$, lending initial support to the hypothesis that a set of MMPI items can be derived to discriminate between the two groups. However, this initial finding should not be interpreted as support for the more general hypothesis that "one salient, unique MMPI item scale (IC) can be empirically derived to identify male incest offerders" (Dolan, 1985). Nor does this finding support the validity of the Ic experimental subscale. None of the 12 items (which were derived by comparing MMPI item responses of male incest offenders and male alcoholics) are the same items which comprise the Ic subscale (derived by comparing the MMPI item responses of male incest offenders and "normal" college males. And, although the Ic subscale had differentiated effectively between incest offenders and "normal" males in a previous study (Dolan, 1985), in the present study it failed to differentiate between incest offenders and alcoholics, misclassifying slightly more alcoholics as 
offenders (63.75\%) than correctly classifying offenders $(62.5 \%)$.

Nor does this study support the validity of the SV or Pe subscales. First, none of the 12 items derived in this study appears in the Pe subscale, and only 31 tems (37, 39, and 98) overlap, endorsed in the same direction, with the Sv subscale. Second, neither the Sv nor the Pe subscale discriminated effectively between the offenders and alcoholics in this study, misclassifying $77.5 \%$ and $57.5 \%$ of the alcoholics, respectively. This finding is consistent with the previous cross-validation research which demonstrated that (although the subscales had differentiated sexual offenders from "normal" males) both subscales falled to differentiate offenders from populations with other types of psychopathology (Holz et al., 1957; Marsh et al., 1955; Peek \& Storms, 1956; Toobert et al., 1959; Wattron, 1958; Yamahiro \& Griffith, 1960).

It also needs to be noted that, due to a probable but unknown base rate of undisclosed incest offenders among the general population, the findings of this study (and of the prevlous studies) are likely confounded. Such a base rate of offenders among the nonoffender comparison groups would have affected the validity of the final set of discriminating items (as well as the validity of the $\underline{I C}, \underline{S v}$, and $\underline{P e}$ subscales). 
Furthermore, such a base rate would likely have impaired the scoring accuracy of each of the derived scales.

This study, therefore, reconfirmed previous research which failed to validate MMPI scales for the identification of sex offenders. This consistent failure offers strong evidence that the MMPI is not a suitable tool for differentlating between the complex psychopathological variables involved in deriving a scale to discriminate sex offenders from both "normal" and pathological males. Additional evidence for this hypothesis is offered by the fact that this study and each of the previous studies has produced a different set of discriminating items. Of the 11 IC items, 9 appear in the 100-item Sv subscale (but only 4 of these 9 items also appear in the Pe subscale). Of the 24 Pe items, only 10 items overlap with $\underline{\text { sv }}$ subscale. This moderate overlap between the three subscales may be due to the fact that all three were derived using control groups of "normal" males. Of the three, however, the pe subscale overlaps least, likely reflecting the fact that it was derived using an additional control group of male felons with psychopathology.

Similarly, the final set of 12 items derived in this study overlaps with only 3 of the 100 items in the sv subscale. The greater uniqueness in this final set of discriminating items seems to have resulted from the 
comparison of offender psychopathology with the psychopathology of a control group of male alcoholics. These findings suggest that no one set of MMPI items will differentiate sex offenders (or incest offenders) from all other groups, but that different items will differentiate in different studies, depending upon the nature and psychopathology of the various control groups involved. As previous researchers have suggested, discriminating MMPI items seem to be measuring some other "factor of personality integration" rather than sexual deviancy (Marsh et al., 1955).

It should be noted that the design of the present study precluded the 1dentification of many MMPI items which might be related to personality traits and psychopathology common to both the incest offenders and the alcoholics. Nonetheless, it is tempting to inspect the verbal content of the final set of derived items to compare with previous hypotheses about of fender personality traits (see Table VI). Although 7 of the 12 items are from clinical scales 2 (Depression) or 4 (Psychopathic Deviate), the majority of the offenders answered only 2 of these items in the scoring direction, admitting to trouble because of sex behavior (item 37; scale 4) but denying feelings of aggressive anger (1tem 39; scale 2 and special scale $\underline{R}$--Repression). The verbal content of item 37 (trouble because of sex behavior) 
makes it an item that most incest offenders would likely find useless to deny. Similarly, the verbal content of Items 215 and 460 concerns alcohol consumption, and the response pattern of both the offenders and the alcoholics (50\% of the offenders admitted to excessive use of alcohol, $78 \%$ admitted to only moderate or no use of alcohol, while 99\% of the alcoholics admitted to excessive use of alcohol) likely reflects the futility of denying obvious pathological symptoms. However, item 39 seems to Indicate denial and repression of anger and hostility. Similar repression and denial of pathological symptoms by offenders may be reflected by non-scoring responses to items $8,9,36$, and 277 . These 1tem responses seem consistent with descriptions of offenders which have noted poor impulse control and lack of sexual discipline (Weinberg, 1955), unconscious hostility (Cavalin, 1966), and frequent substance abuse (Gebhard et al.. 1965; Herman \& Hirschman, 1981). In addition, item 98 was answered by the majority of offenders in the scoring direction for special scales Dy (Dependency) and REL (Religious Fundamentalism). This item response is consistent with previous studies which have noted dependent personality traits (Anderson \& Shafer, 1979; Gebhard et al., 1965; Justice \& Justice, 1979) and strong religious concerns (Toobert et al., 1959) among incest offenders. 
The most frequently elevated MMPI clinical scale among the offenders in this study was scale 4 (often associated with persons who may be impulsive, emotionally shallow, and socially nonconforming) followed by scale 2 (often associated with persons who may be depressed, anxious, withdrawn, soclally isolated, and experiencing somatic symptoms). These findings are only partly consistent with the previous studies which also found frequent elevations on scale 6 (Paranola) (Langevin, et al., 1978), scales 8 (Schizophrenta) and 9 (Hypomanta) (Armentrout \& Hauer, 1978), and scale o (Social Introversion) (Panton, 1979). However, each of the ten clinical scales were elevated in this study by 5 or more of the offenders, suggesting a wide range of personality traits and psychopathology. In addition, the finding of no modal high-point pair is consistent with previous studies which have hypothesized that no one high-point pair characterizes male incest offenders (Armentrout \& Hauer, 1978; Dolan, 1985). Perhaps 1t should be further hypothesized that no one personality pattern may be typical of the incest offender. Rather, offenders may exhibit a wide variety of personality factors, including many differing kinds of psychopathology. Consequently. it might follow that no one MMPI scale can be derived to discriminate offenders from all other populations.

The demographic data (see Table II) indicated that 
incest offenders and alcoholics may have experienced similar amounts of childhood disruption and deprivation due to parental divorce or lack of affection. However, It is noteworthy that offenders reported significantly more physical and sexual abuse. Though the alcoholics reported significantly more parental alcoholism, 24\% of the incest offenders also reported alcoholic parents. These findings once again corroborate studies demonstrating that a high percentage of sexual offenders have come from emotionally deprived and abusive backgrounds.

A comparison made to investigate potential differences in the abusive patterns of incest offenders who were fathers versus incest offenders who were stepfathers or father surrogates, produced no significant differences (see Table III). The data indicate that both fathers and stepfathers typically began abusing daughters or daughter-surrogates near the onset of puberty, and continued until disclosure or until the daughter was old enough to resist. The comparable abusive pattern is consistent with previous research findings comparing father offenders with stepfather or father surrogate offenders.

Scoring by the MAC (MacAndrew Alcoholism) scale was not a primary aspect of this study. However, the alcoholic control group made possible a supplementary 
investigation of this scale. Although the MAC scale correctly classified $63.76 \%$ of the alcoholics, it misclassifled $40 \%$ of the nonalcoholic offenders. These findings are similar to those reported by Uecker (1970) where $69.5 \%$ of the alcoholics were classified correctly, but $55.5 \%$ of a psychiatric control group were misclassified. Similarly, Schwartz and Graham (1979) found that MAC scores did not differ significantly between a sample of male alcoholics and male psychiatric patients and hypothesized that "the MAC may assess personality characteristics of impulsivity. noninsightfulness, nondefensiveness, and general psychological maladjustment" (p. 1094.) A1though the MAC scale has been successful in differentiating alcoholics from nonalcoholic psychiatric patients in a variety of studies (see references in Greene, 1980, p. 194), the failure of the scale to discriminate between alcoholics and nonalcoholic offenders in this study raises questions about the scale's validity which may warrant further investigation.

In summary, this study did not support the validity of previously-derived MMPI scales for the identification of sex offenders, including the more recently-derived Iㄷ subscale for the ldentification of incest of fenders. Although 12 MMPI items discriminated between male incest offenders and male alcoholics, these items differed 
entirely from the items comprising the Ic subscale. This finding did not support the hypothesis that an MMPI scale can be empirically derived for the Identiflcation of male incest offenders (Dolan, 1985). In addition, the IC, SV, and Pe subscales all falled to discriminate effectively between the incest offenders and the alcoholics. These findings replicated previous failures to cross-validate MMPI subscales for the identification of sexual offenders.

Due to the nature of incest and factors surrounding the taboo le.g, secrecy, shame, privacy, and fear of disclosure), incest is difficult to detect, and may continue for several years (often with successive children and through successive generations), prior to detection. The literature review demonstrated that the majorlty of researchers have found incest to be harmful, especially to the child, but also to the entire family, including the offender. Because of the sensitivity of incest and the stigma involved in child sexual abuse, it is important that a scale for the identification of offenders be valid and reliable. Although the 12 items derived in this study might be worthy of further research, the results of the present study strongly indicated that the MMPI is not a suitable instrument for the derivation of such a scale. 


\section{REFERENCES}

American Psychlatric Association. (1980). Diagnostic and statistical manual of mental disorders. (3rd ed.) Washington, DC: Author.

Anderson, L. M., \& Shafer, G. (1979). The characterdisordered family: A community treatment model for family sexual abuse. American Journal of Orthopsychiatry, 49, 436-445.

Anderson, W. P., Kunce, J. T., \& Rich, B. (1979). Sex offenders: Three personality types. Journal of Clinical Psychology, 35, 671-676.

Armentrout, J. A., \& Hauer, A. L. (1978). MMPIs of rapists of adults, rapists of children, and non-raplst sex of fenders. Journal of Clinical Psychology, 34, 330-332.

Arroyo, W., Eth, S., \& Pynoos, R. (1984). Sexual assault of a mother by her preadolescent son. American Journal of Psychiatry, 141. 1107-1108.

Banmen, J. (1982). The incidence, treatment and counseling of incest. International Journal for the Advancement of Counseling, 5, 201-206.

Becker, J. V., Skinner, L. J., Abel, G. G., Axelrod, R., \& Cichon, J. (1984). Sexual problems of sexual assault survivors. Women \& Health, 9, 5-20.

Bender, L., \& Blau, A. (1937). The reaction of children to sexual relations with adults. American Journal of Orthopsychiatry, I, 500-518.

Breines, W., \& Gordon, L. (1983). The new scholarship on family violence. Signs: Journal of Women in Culture and Society, $8,490-531$.

Brooks, B. (1985). Sexually abused children and adolescent identity development. American Journal of Psychotherapy, 39, 401-409. 
Brown, S. (1979). Clinical illustrations of the sexual misuse of girls. Child Welfare, 58, 435-442.

Cavaliin, H. (1966). Incestuous fathers: A clinical report. American Journa 1 of Psychiatry, 122, 1132-1138.

Clopton, J.R. (1978). MMPI scale development methodology. Journal of Personality Assessment, 42, 148-151.

Clopton, J.R. (1982). MMPI scale development methodology reconsidered. Journal of Personality Assessment, 46, 143-146.

Cohen, T. (1983). The incestuous family revisited. Soclal Casework: The Journal of Contemporary Soclal Work, 64, 154-161.

Cole, E. (1982). Sibling incest: The myth of benign sibling incest. Women \& Therapy, 1, 79-89.

Dahlstrom, W. G., \& Welsh, G. S. (1960). An MMPI handbook--A guide to use in clinical practice and research. Minneapolis: University of Minnesota Press.

Dixon, K. N., Arnold, L. E., \& Calestro, K. (1978). Father-son incest: Underreported psychiatric problem? American Journal of Psychiatry, 135, 835-838.

Dolan, M. S. (1985). The MMPI: A subscale (Ic) for the identification of male incest offenders. Unpublished master's thesis, Portland state University, Portland, OR.

Finkelhor, D. (1978). Psychological, cultural and family factors in incest and family sexual abuse. Journal of Marriage and Family Counseling, 4 , 41-49.

Finkelhor, D. (1981). Sex between siblings: Sex play, incest, and aggression. In Constantine, L. L., \& Martinson, E. M. (Eds.), Children and Sex: New findings, new perspectives. Boston: Little, Brown and Company.

Finkelhor, D. (1984). Sexual abuse in the National Incidence Study of Child Abuse and Neglect: An appraisal. Child Abuse \& Neqlect, $8,23-33$. 
Fowler, C., Burns, S. R., \& Roehl, J. E. (1983). Counseling the incest offender. International Journal of Family Therapy, 5, 92-97.

Freud, S. (1946). Totem and taboo (A. A. Brill, Trans.). New York: Random House. (Original work published in 1913).

Gebhard, P. H., Gagnon, J. H., Pomeroy, W. B., \& Christenson, C. V. (1965). Sex offenders: An analysis of types. New York: Harper \& Row.

Gelinas, D. J. (1983). The persisting negative effects of incest. Psychiatry, 46, 312-332.

Graham, J . R. (1977). The MMPI: A practical guide. New York: Oxford University Press.

Green, C. M. (1982). Filicidal impulses as an anniversary reaction to childhood incest. American Journal of Psychotherapy, 36, 264-271.

Greene, R. L. (1980). The MMPI: An Interpretive Manual. Orlando, FL: Grune \& stratton.

Gross, M. (1979) Incestuous rape: A cause for hysterical seizures in four adolescent girls. American Journal of Orthopsychiatry, 49 , 704-708.

Herman, J., \& Hirschman, L. (1981). Families at risk for father-daughter incest. American Journal of Psychiatry, 138, 967-970.

Holz, W. C.. Harding, G. F. \& Glassman, S. M. (1957). A note on the clinical validity of the Marsh-Hilliard-Liechti MMPI sexual deviation scale. Journal of Consulting Psychology, 21, 326 .

James, J., \& Meyerding, J. (1978). Early sexual experience as a factor in prostitution. Archives of Sexual Behavior, 1 , 31-42.

Justice, B., \& Justice, R. (1979). The broken taboo: Sex in the family. New York: Human Sciences Press.

Kempe, C.H. (1978). Sexual abuse, another hidden pediatric problem: The $1977 \mathrm{C}$. Anderson Aldrich lecture. Pediatrics, 62, 382-389. 
Kirkland, K. D., Bauer, C. A. (1982). MMPI traits of incestuous fathers. Journal of Clinical

Psychology, 38, 645-649.

Langevin, R. , Paitich, D., Freeman, R. , Mann, K. , \& Handy, L. (1978). Personality characteristics and sexual anomalies in males. Canadian Journal of Behavioral science, 10, 222-238.

Langsley, D. G., Schwartz, M. N., \& Fairbairn, R. H. (1968). Father-son incest. Comprehensive

Psychiatry, $9,218-226$.

Levison, P. K., Gerstein, D. R., Maloff, D. R. (Eds.). (1983). Commonalities in substance abuse and habitual behavior. Lexington, Mass.: Lexington Books.

Lévi-strauss, C. (1969). The elementary structures of kinship (rev. ed.). Boston: Beacon Press.

IIndzey, G. (1967). Some remarks concerning incest, the incest taboo, and psychoanalytic theory. American Psychologist, 22, 1051-1059.

Lukianowicz, N. (1972). Paternal incest. British Journal of Psychiatry, 120, 301-313.

Lustig, N., Dresser, J. W. , Spellman, S. W. \& Murray, T. B. (1966). Incest: A family group survival pattern. Archives of General Psychlatry, 14. $31-40$.

Machotka, P., Pittman, F. S., \& Flomenhaft, K. (1967). Incest as a family affair. Family Process. 6 , 98-116.

Margolis, M. (1984). A case of mother-adolescent son incest: A follow-up study. Psychoanalytic Quarterly, 53, 355-385.

Marsh, J. T., Hilliard, J., Liechti, R. (1955). A sexual deviation scale for the MMPI. Journal of Consulting Psychology, 19, 55-59.

Maynard, H. M. (1984, March). The cycle of abuse (Cassette Recording). Keynote address presented at the Third Annual Northwest Conference on Child Sexual Abuse, Portland State University, Portland, OR. 
Maynard, H. M. (1985, April). Mystery and terror: The plight of the victim (Cassette Recording).

Keynote address presented at the Fourth Annual Northwest Conference on Child Sexual Abuse, Portland State University, Portland, OR.

Maynard, H. M. (1986, April). On the origins of child sexual assault (Cassette Recording). Keynote address presented at the Fifth Annual Northwest Conference on Child Sexual Abuse, Portland State University, Portland, OR.

O'Hare, J., \& Taylor, K. (1983). The reality of incest. Women \& Therapy, 2, 215-229.

Oregon. Legislative Counsel Committee. (1985). oregon Revised Statutes. Salem, OR.: Author.

Panton, J.H. (1979). MMPI profile configurations associated with incestuous and non-incestuous child molesting. Psychological Reports, 45, 335-338.

Parker, S. (1976). The precultural basis of the incest taboo: Toward a blosocial theory. American Anthropologist, 78, 285-305.

Peek, R. M., \& Storms, L. H. (1956). Valldity of the Marsh-Hilliard-Liecht1 MMPI sexual deviation scale in a state hospital population. Journal of Consulting Psychology, 20, 133-136.

Raybin, J. B. (1969). Homosexual incest. The Journal of Nervous and Mental Disease, 148, 105-110.

Renshaw, D. C. (1982). Incest: Understanding and treatment. Boston: Iittle, Brown.

Russel1, D. E. (1983). The incldence and prevalence of intrafamilial and extrafamilial sexual abuse of female children. Child Abuse \& Neglect, $\underline{z}$. 133-146.

Scherzer, L. N. \& Lala, P. (1980). Sexual offenses committed against children. Clinical Pediatrics, $19,679,683-685$.

Schwartz, M. F., Graham, J.R. (1979). Construct validity of the MacAndrew Alcoholism Scale. Journal of Consulting and Clinical Psychology, 47, 1090-1095. 
Sgroi, S. M. (1982). Handbook of clinical intervention in child sexual abuse. Lexington, Mass.: D. C. Heath.

Toobert, S. Bartelme, K. F.. Jones, E. S. (1959). Some factors related to pedophilia. International Journal of Social Psychiatry, 4 , 272-279.

Uecker, A. E. (1970). Differentiating male alcoholics from other psychiatric inpatients: Validity of the MacAndrew scale. Quarterly Journal of studies on Alcohol, 31, 379-383.

Vaillant, G. E. (1983). The natural history of alcoholism. Cambridge: Harvard University Press.

Vander Mey, B. J., \& Neff, R. I. (1982). Adult-child incest: A review of research and treatment. Adolescence, 17, 717-735.

Vander Mey, B. J., \& Neff, R. L. (1984). Adult-child incest: A sample of substantlated cases. Family Relations, 33, 549-557.

Watson, R., Lubenow, G. C., Greenberg, N. F., King, P., \& Junkin, D. (1984, May 14). Sexual abuse--a

hidden epidemic. Newsweek, pp. 30-36.

Wattron, J. B. (1958). Validity of the Marsh-HilliardLiechti MMPI sexual deviation scale in a state prison population. Journal of Consulting Psychology, 22, 16 .

Webster's New Collegiate Dictionary. (1973). Springfield: G. C. Merriam.

Weinberg, S. K. (1955). Incest behavior. New York: citadel.

Westermeyer, J. (1978). Incest in psychiatric practice: A description of patients and incestuous relationships. Journal of Clinical Psychiatry. 39, 643-648.

Yamahiro, R. S., Griffith, R. M. (1960). Validity of two Indices of sexual deviancy. Journal of clintcal Psychology, 16, 21-24. 
Yorukoglu, A., \& Kemph, J. P. (1966). Chlldren not severely damaged by incest with a parent. Journal of the American Academy of Child Psychiatry, 5, 111-124. 